\title{
Surgical management of gynaecomastia by using cross chest liposuction and limited periareolar incision for gland excision: an interesting case report
}

\author{
Madhusoodan Gupta ${ }^{1 *}$, Deepti Varshney ${ }^{2}$
}

\author{
${ }^{1}$ Department of Plastic Surgery, Sri Sai Superspeciality Hospital, Moradabad, Uttar Pradesh, India \\ ${ }^{2}$ Department of Pathology, Pathkind labs Moradabad, Uttar Pradesh, India
}

Received: 13 August 2021

Accepted: 09 August 2021

*Correspondence:

Dr. Madhusoodan Gupta,

E-mail: drmsgupta12@gmail.com

Copyright: (c) the author(s), publisher and licensee Medip Academy. This is an open-access article distributed under the terms of the Creative Commons Attribution Non-Commercial License, which permits unrestricted non-commercial use, distribution, and reproduction in any medium, provided the original work is properly cited.

\begin{abstract}
Gynaecomastia is excessive or abnormal enlargement of male breast tissue. It is one of a common problem among young men. The term gynaecomastia means female like enlargement of male breast due to increase ductal tissue, stroma or fat. Most common cause of gynaecomastia is idiopathic. Surgical treatment of gynaecomastia involves liposuction and glandular excision and in few cases skin excision. Here author presents a case of 24 years old young healthy male with Simon's grade 2B bilateral gynaecomastia. He had stubborn fat over bilateral chest which was resistant to exercise. Gynaecomastia was mixed type in characteristic having adipose tissue as well as glandular tissue enlargement. Bilateral liposuction and glandular excision by limited periareolar incision under general anesthesia as a day care procedure was done. In our procedure we used Cross chest liposuction. Patient was discharged at the same evening without any complications. After four months of follow up patient has male pattern chest with almost invisible scar and intact Nipple areolar complex (NAC) sensation.
\end{abstract}

Keywords: Gynaecomastia, Ductal tissue, Stroma, Cross chest liposuction, Nipple areolar complex

\section{INTRODUCTION}

Gynaecomastia is excessive or abnormal enlargement of male breast tissue. It is one of a common problem among young men. The term gynaecomastia means female like enlargement of male breast due to increase ductal tissue, stroma or fat. Gynaecomastia causes social embarrassment, low self esteem and anxiety. It has little risk for malignant transformation. Generally it occurs at the time of hormonal changes in the body such as infants, adolescence and old ages. Most common cause of gynaecomastia is idiopathic. Transiently it occurs at infancy due to increase level of circulating maternal estrogen, which resolve later on once estrogen level normalize. Gynaecomastia occurs in almost two thirds of young boys. ${ }^{1}$ This is due to imbalance between estrogen and testosterone. Most of the cases of gynaecomastia resolve spontaneously in young boys without any treatment. $^{2}$ But in few cases gynaecomastia persist and requires surgical management. Surgical treatment of gynaecomastia involves liposuction and glandular excision and in few cases skin excision. ${ }^{3,4}$ Surgical treatment depends on grades of gynaecomastia. Simon's classified gynaecomastia into grade 1-small enlargement of breast no excess skin, 2A- moderate enlargement of breast no excess skin, 2B- moderate enlargement with extra skin, 3- marked enlargement with extra skin. ${ }^{5}$ Here author presents a case of 24 years old young healthy male with grade $2 \mathrm{~B}$ bilateral gynaecomastia. He had stubborn fat over bilateral chest which was resistant to exercise since 3 years. Surgical procedure in the form of bilateral cross chest liposuction and glandular excision by limited 
periareolar incision was done. Patient was discharged at the same evening without any complications. After four months of follow up patient has male pattern chest with almost invisible scar and intact Nipple areolar complex (NAC) sensation.

\section{CASE REPORT}

Author presents a case of 24 years old young male who had grade $2 \mathrm{~B}$ bilateral gynaecomastia. Detailed history and physical examination were done.

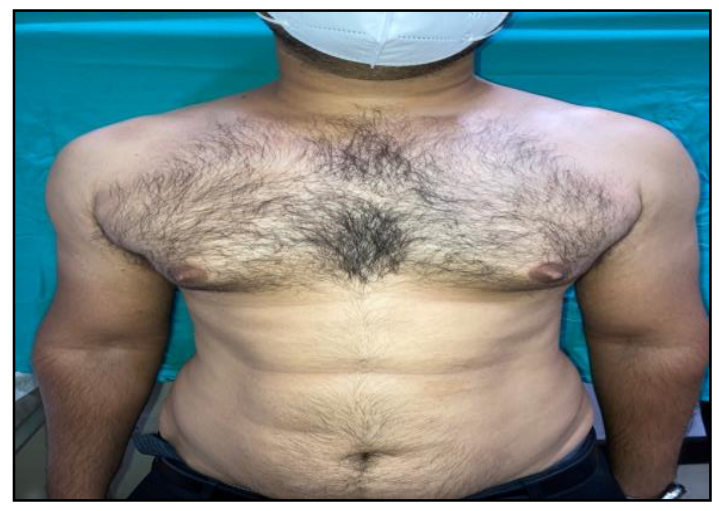

Figure 1: Preoperative front view.

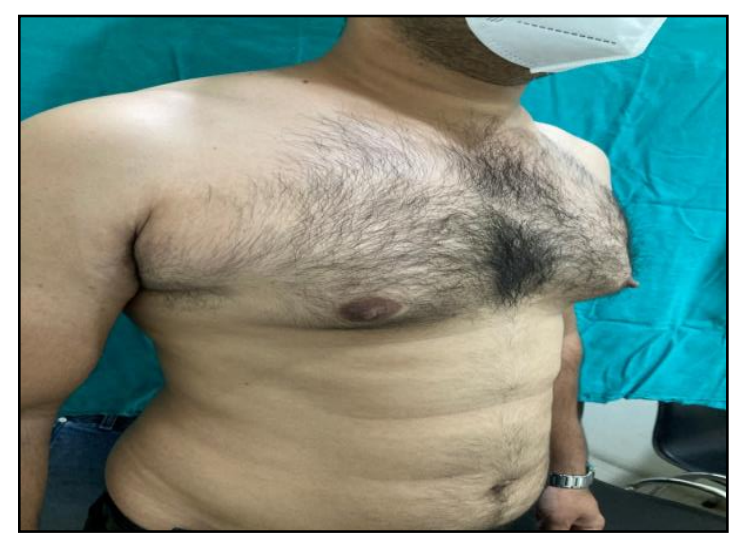

Figure 2: Right oblique view.

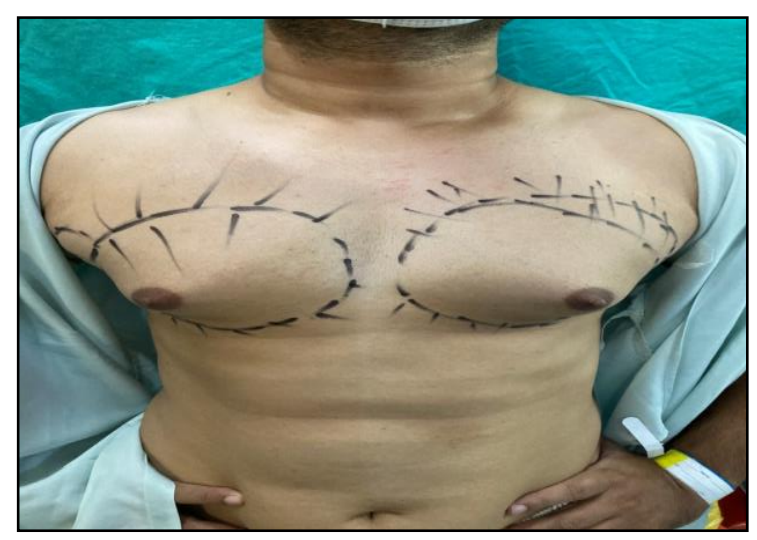

Figure 3: Simons grade 2B gynaecomastia with marking.

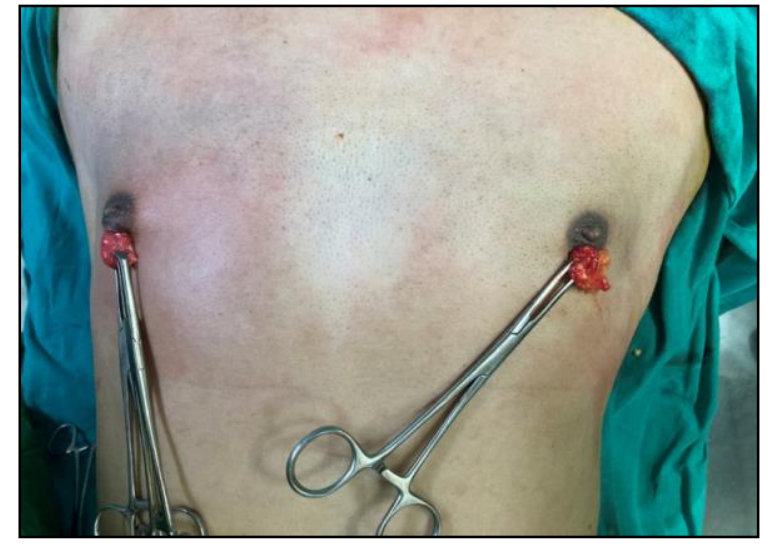

Figure 4: Bilateral gland excision with limited periareolar incision.

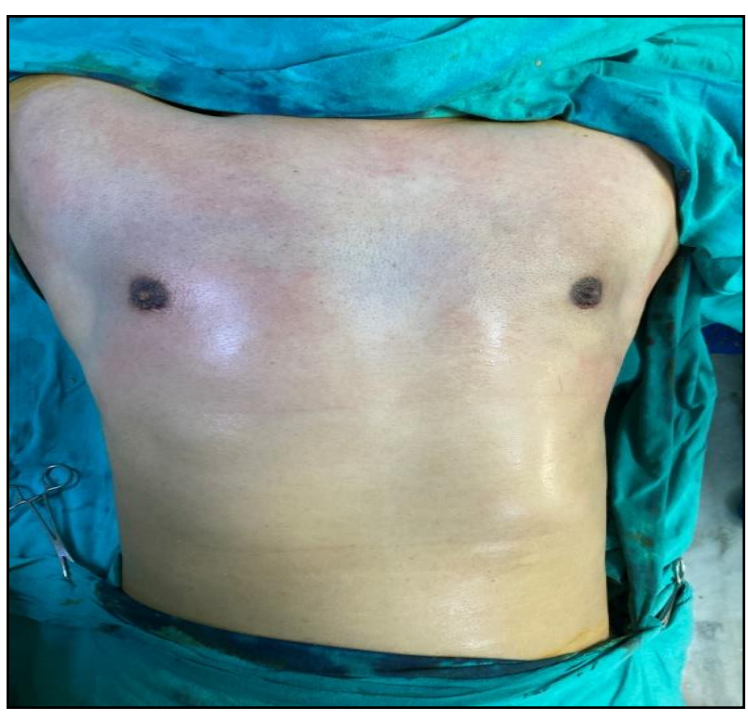

Figure 5: Immediate post operative result.

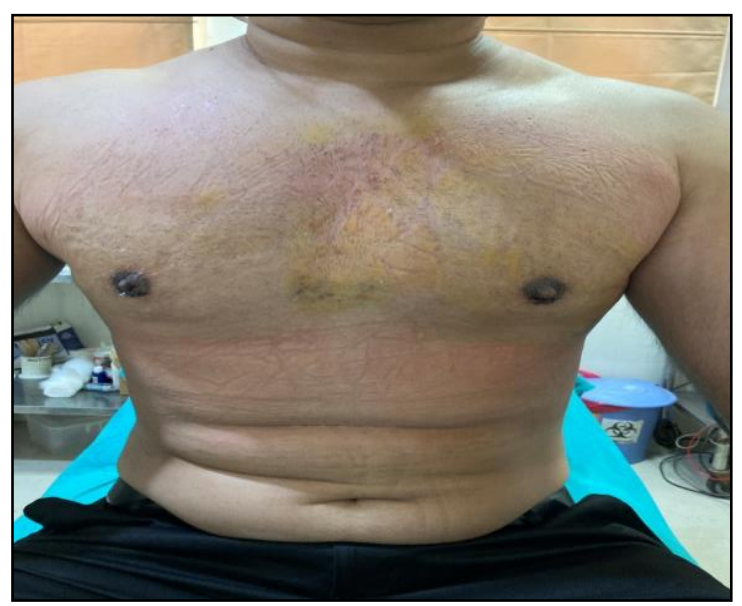

Figure 6: Postoperative day 5 result.

History was taken regarding the time of onset of gynaecomastia, duration, symptoms associated with gynaecomastia and any drug used. Physical examination was done including assessment of breast gland, nature of 
breast tissue, any palpable mass, tenderness, nipple discharge, axillary lymph node enlargement, testicular examination for size, symmetry, enlargement and any solid mass. After ruling out the other causes, diagnosis of idiopathic gynaecomastia with Simon's grade 2B was made (Figure 1,2).

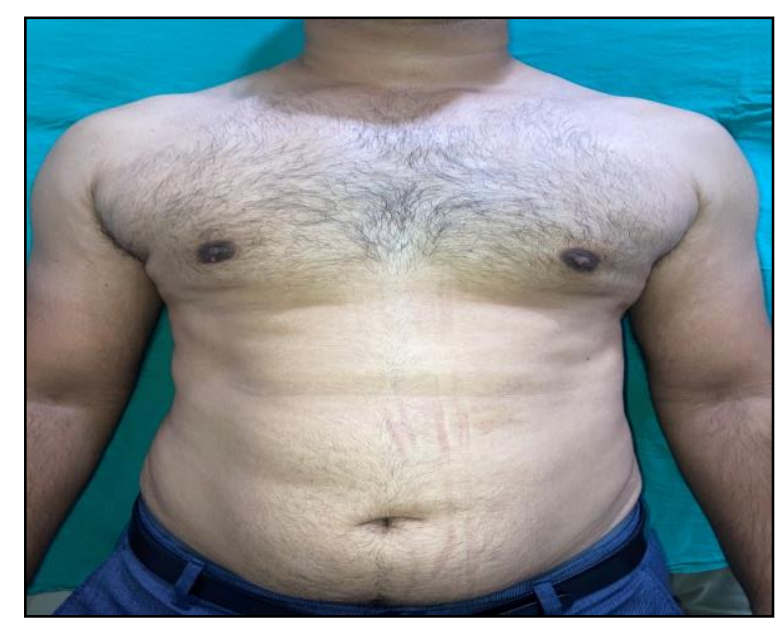

Figure 7: Four months follow up front view.

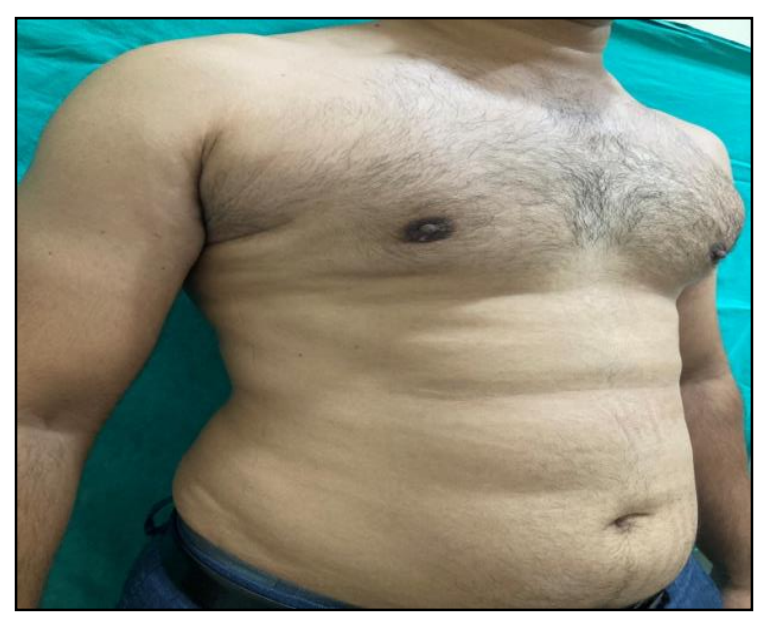

Figure 8: Four months follow up right oblique view.

Gynaecomastia was mixed type in characteristic having adipose tissue as well as glandular tissue enlargement. Surgical procedure was explained in details to the patient and his relatives. Informed consent was taken. Preanaesthetic checkup and routine blood investigations were done. Bilateral axillary hair and chest hair were trimmed. Patient took bath at the morning of surgery. Marking was done in upright position (Figure 3). Patient was kept supine with his both arm in abduction. General anesthesia was given. Parts painted and draped. Tumescent anesthetic solution was made with standard fashion. Tumescent solution was prepared by mixing 1 litre of physiological solution with $1 \mathrm{ml}$ adrenaline $(1: 1000)$ plus $20 \mathrm{ml} 2 \%$ xylocaine and $10 \mathrm{ml} 8.4 \%$ sodium bicarbonate. Stab incision was made bilaterally at 6 o clock position at the junction of areola and normal skin. $500 \mathrm{ml}$ tumescent anesthetic solution was infiltrated in each side. After waiting for 7 minutes liposuction was started. Initially liposuction was started from the deep subcutaneous plane with 4- mm cannula followed by superficial plane with $3 \mathrm{~mm}$ cannula. After that fine contouring and skin tightening was done with $3 \mathrm{~mm}$ and $2 \mathrm{~mm}$ cannulas. Pale yellow color fat was noticed in suction tube. Cross chest liposuction was done. Skin fold thickness between the thumb and index finger was measured various times to know the equal thickness of skin and subcutaneous tissue. Cross hatching was done. Special attention was given to axillary tail region. Stab incision was extended from $5 \mathrm{o}$ clock to 7 o clock position also known as limited periareolar incision. Nipple areolar complex (NAC) is retracted upwards with skin hooks. Special care was given to keep the $1 \mathrm{~cm}$ cuff of tissue under the nipple areolar complex to prevent post operative depression and sensory loss of NAC. Glandular tissue was hold and retract with babcock forceps. Under vision, dissection was done with bipolar cautery to get good haemostasis. Gradually complete glandular tissue excision was done (Figure 4). After excision haemostsis confirmed. Same procedure was repeated to other site. Wound was closed in layers with 40 Monocryl and 6-0 Prolene(Figure 5). Small dressing over NAC was done. Pressure garment was wore to patient at operation table. Patient was smoothly extubated and shifted in postoperative care ward. Patient was discharged at the same evening without any complications. Patient followed up at post op day 5, no hematoma or seroma was found and all sutures were removed (Figure 6). After 4 month of follow up patient has male pattern chest with inconspicuous scar and intact NAC sensation (Figure 7,8).

\section{DISCUSSION}

Galen was first to use the term Gynaecomastia or enlargement of male breast in the 2 nd century AD. Upto $60 \%$ of young boys have gyaenecomastia. ${ }^{6}$ Surgical treatment depends on Simons grade of gynaecomastia. Treatment of Grade 1 is liposuction only in case of fat predominance gynaecomastia. Treatment of Grade 2A and $2 \mathrm{~B}$ are liposuction along with glandular excision in good quality of skin. Grade 3 and few cases of grade 2B also require liposuction with gland excision as well as skin excision. ${ }^{7,8}$ The Aim of Gynaecomastia surgery is to achieve male pattern chest with inconspicuous scar and well preserve sensation of NAC. Author used the technique cross chest liposuction and glandular excision with limited periarealar incison. In our case we obtained good aesthetic result with male pattern chest with almost invisible scar with intact NAC sensation in follow up. Cross chest liposuction is useful surgical technique in bilateral gynaecomastia which decreases the scar formation without any disadvantage.

\section{CONCLUSION}

Gynaecomastia surgery is an aesthetic surgery. Bilateral cross chest liposuction and gland excision by limited periareolar incision is a noval technique. It provides good aesthetic results with male pattern chest and very 
inconspicuous scar formation as well as intact sensation of NAC. But this technique is limited to Simons grade $2 \mathrm{~A}$ and $2 \mathrm{~B}$ only as skin excision can not be done with this technique.

Funding: No funding sources

Conflict of interest: None declared

Ethical approval: Not required

\section{REFERENCES}

1. Nydick M, Btos J, Dale JH, Rawson RW. Gynaecomastia in adolescent boys. JAMA. 1961;178:449.

2. McGrath MH. Gynecomastia. In: Jurkiewicz MJ, MatheJ SJ, Krizek TJ, Ariyan S, eds. Plastic Surgery: Principle and Practice. St. Louis, MO: Mosby. 1990;1119.

3. Maladick RA. Gynecomastia: Liposuction and excision. Clin Plast Surg. 1991;18:815-22.
4. Boljanovic S, Axelsson CK, Elberg JJ. Surgical Treatment of Gynecomastia: Liposuction combined with subcutaneous mastectomy. Scand J Surg. 2003;92:160-2.

5. Simon BE, Hoffman S, Kahn S. Classification and surgical correction of gynaecomastia. Plastic Reconstructive surgery. 1973;51:48.

6. Braunstein GD. Clinical practice: Gynecomastia. N Engl J Med. 2007;357:1229-37.

7. Wiesman IM, Lehman JA Jr, Parker MG, Tantri MD, Wagner DS, Pedersen JC. Gynecomastia: An outcome analysis. Ann Plast Surg. 2004;53:97-101.

8. Fruhstorfer BH, Malata CM. A systematic approach to surgical treatment of gynecomastia. Br J Plast Surg 2003;56:237-46.

Cite this article as: Gupta M, Varshney D. Surgical management of gynaecomastia by using cross chest liposuction and limited periareolar incision for gland excision: an interesting case report. Int Surg J 2021;8:3220-3. 